\title{
Comparison of the Compressive Strength of Impregnated and Nonimpregnated Eucalyptus Subjected to Two Different Pressures and Impregnation Times
}

\author{
Waldemir Rodrigues, Mariano Martínez Espinosa*, Wagner Luis Polito \\ São Carlos School of Enginnering, University of São Paulo, USP \\ C.P. 359, 13566-590 São Carlos - SP, Brazil
}

Received: June 10, 2003; Revised: November 10, 2003

\begin{abstract}
The durability of wood is affected by several factors. For this reason, much research has been done on a variety of chemical compounds for impregnating wood, aimed at preserving it while simultaneously improving its properties. Recent studies of the properties of impregnated wood have demonstrated the possibility of substantially improving its mechanical characteristics. Thus, the purpose of this work was to compare the strength to parallel compression of wooden fibers (Eucalyptus grandis), both nonimpregnated and impregnated with a monocomponent resin, from the standpoint of pressure and impregnation time, aiming at its structural utilization. The results demonstrate that the compressive strength of impregnated test specimens is greater than that of nonimpregnated ones, indicating that monocomponent polyurethane resin can be considered suitable for impregnating wood, since it increases the compressive strength of eucalyptus.
\end{abstract}

Keywords: impregnated wood, wood, compressive strength, analyses of variance

\section{Introduction}

Wood has been employed in a variety of applications, thanks to its useful and very distinct properties ${ }^{1}$, e.g., high mechanical resistance and low density compared with other materials, such as steel. It is, moreover, a renewable resource. However, being a biological material, when exposed, wood is subject to natural wear and to attack by fungi, insects and other types of organisms. These agents can cause considerable damage or defects, varying from stains and alterations in color to loss of mechanical strength and even complete degradation.

One well-known technique to protect wood is by impregnating it with chemical products ${ }^{9}$. Recent studies with resins have shown that castor-oil-based polyurethane resins have innumerable practical applications ${ }^{3}$, especially the monocomponent type of resin, which is a solventless system containing prepolymers with $\mathrm{NCO}$ termination that cure upon reacting with ambient humidity ${ }^{5}$. In the specific case of monocomponent polyurethane resin, because it is a new material and has not yet been applied on wood, its compo- sition must be studied, aiming at its introduction as an alternative to other composites. This requires a preevaluation of its performance as a modifier of impregnated wood. The composite formed between wood and polymer obtained by impregnation with liquid monomers, when polymerization occurs inside the wood, has been studied for several years and may become a promising alternative for improving the physical and mechanical properties of wood $^{2}$. The purpose of this work was to compare the compressive strength of nonimpregnated wood with that of wood impregnated with monocomponent resin under different pressures and impregnation times.

\section{Material and Methods}

This study was carried out in the Laboratory of Wood and Wooden Structures (LaMEM) of the São Carlos School of Engineering (EESC), University of São Paulo (USP), state of São Paulo, Brazil.

The wood under study was Eucalyptus grandis and the 
test specimens, $20 \mathrm{~mm}(0.78 \mathrm{in}$.) thick, $20 \mathrm{~mm}(0.78 \mathrm{in}$.) wide, and $60 \mathrm{~mm}$ (2.36in.) long, were taken from a beam with a moisture content of about $12 \%$, according to the Brazilian code NBR 7190/978 (see Fig. 1).

The resin employed to impregnate the specimens was monocomponent resin, which is a prepolymer with $\mathrm{NCO}$ termination that cures upon reacting with the humidity in the air.

The method used to impregnate the wood was total immersion in a liquid impregnator (Fig. 2), subjecting the test specimens to a vacuum for $30 \mathrm{~min}$ at constant pressures of $0.5 \mathrm{MPa}$ an $1 \mathrm{MPa}$, and impregnation times of 15 and $30 \mathrm{~min}$, and subsequent drying in an oven (OD) and in air (AD). The compression tests parallel to the fibers were performed according to the Brazilian standard NBR 7190/978, using 6 impregnated and 6 nonimpregnated specimens for each testing condition.

The mechanical tests were carried out in an Amsler universal testing machine with a nominal load capacity of $50 \mathrm{kN}$, belonging to the LaMEM laboratory.

The main objective of this work is to verify if there is significant difference between the means wood strength compression of nonimpregnated and impregnated wood with a monocomponente resin. In order to do this, an appropri-

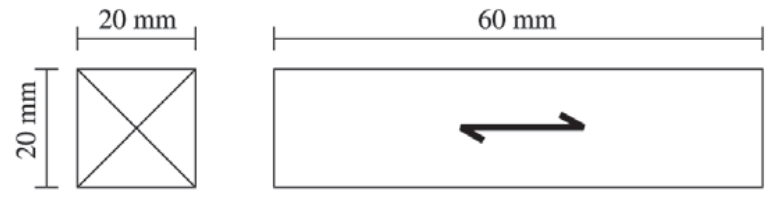

Figure 1. Dimensions of the test specimens.

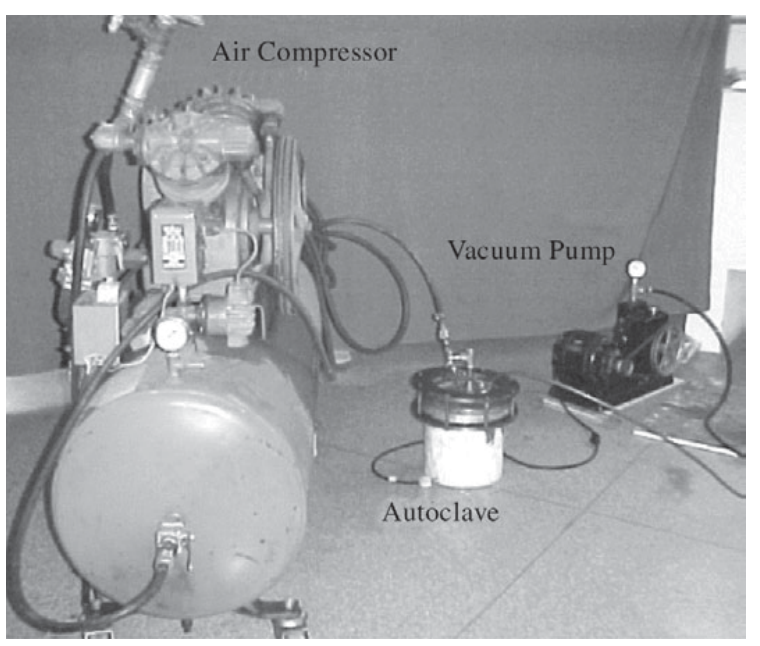

Figure 2. System used to impregnate the wood. ate procedure is to use a completely randomized design, besides considering a statistical model. The statistical model of this design is given by the following relationship:

$$
y_{t i}=\eta+\tau_{t}+\varepsilon_{t i}
$$

where $y_{t i}$ is the $(t i)$ th observation, for $t=1, \cdots, k$ and $i=1, \cdots, n_{t}$ and $k$ represents the number of treatments and $n_{t}$ the number of observations for treatment. $\mathrm{h}$ is a parameter common to all treatments called the overall mean, $t$ is a parameter unique to the $i$ th treatment called the $i$ th treatment effect, e $e_{t i}$ is a randon error of the model. Our objetives will be to test appropriate hypoteses about the treatment effects and to estimate them. For hypotesis testing, the model errors are assumed to be normally and independently distributed randon variables with mean zero and constant variance $\mathrm{s}^{2}\left(\left(\mathrm{~N}\left(0, \mathrm{~s}^{2}\right)\right)^{6}\right.$.

Observe that before using this model it is necessary an adequacy checking of the assumed model. The residual analysis is the major tool used in this diagnostic checking. The residual for a completely randomized design is given by:

$$
\hat{e}_{i j}=y_{t i}-\bar{y}_{t}+\bar{y}=y_{t i}-\hat{y}_{t i}
$$

where $\hat{y}_{t i}=\bar{y}_{t}-\bar{y}$. With this analysis, it is possible to verify, if the assumptions on the residuals $\left(\varepsilon_{t i}\right)$ of the model given by the Equation 1 are valid. In others words, to verify if the assumptions of variance equality are normally and independently accomplished. The validity of these assumptions can be verified by constructing graphs of the residuals $\left(\hat{e}_{i j}\right)$ against the fitted values $\left(\hat{y}_{i j}\right)$ and of the normal scores ${ }^{4}$. If the statistical model is adapted, the table of analyzes of variance is used to test that the means of the treatments are equal ${ }^{6}$. Therefore, a examination of the residuals must be an automatic part of any analysis of variance ${ }^{7}$.

\section{Results and Discussion}

Table 1 presents the wood strength compression values in specimens, both nonimpregnated and impregnated with a monocomponent resin, subjecting the test specimens to a vacuum for $30 \mathrm{~min}$ at constant pressures of $0.5 \mathrm{MPa}$ an $1 \mathrm{MPa}$, and impregnation times of 15 and $30 \mathrm{~min}$, and subsequent drying in an oven (OD) and in air (AD).

Table 2 presents the mean values $(\bar{x})$, standard deviation (s), coefficient of variation (CV) and the estimated characteristic value (ECV) of the impregnated and nonimpregnated test specimens according to the pressures, impregnation times and forms of drying utilized.

As can be seen in Table 2, the specimens impregnated for both 15 and $30 \mathrm{~min}$, dried in the oven and in air, showed higher average values than the nonimpregnated test specimens. The values of the coefficients of variation also reveal that the variability of results of the impregnated specimens 
Table1. The wood strength compression values in specimens, both nonimpregnated and impregnated with a monocomponent resin.

\begin{tabular}{|c|c|c|c|c|c|}
\hline \multirow[t]{2}{*}{$\begin{array}{l}\text { Pressure } \\
(M P a)\end{array}$} & \multirow[t]{2}{*}{ Drying } & \multirow[t]{2}{*}{$\begin{array}{l}\text { Time } \\
\text { (Min) }\end{array}$} & \multirow[t]{2}{*}{ Specimens } & \multicolumn{2}{|c|}{$\begin{array}{c}\text { Strength compression } \\
\text { values in the two } \\
\text { conditions (MPa) }\end{array}$} \\
\hline & & & & I & NI \\
\hline 0.5 & $\mathrm{AD}$ & 15 & 1 & 77.93 & 72.92 \\
\hline 0.5 & $\mathrm{AD}$ & 15 & 2 & 77.29 & 60.17 \\
\hline 0.5 & $\mathrm{AD}$ & 15 & 3 & 91.57 & 52.46 \\
\hline 0.5 & $\mathrm{AD}$ & 15 & 4 & 70.85 & 44.04 \\
\hline 0.5 & $\mathrm{AD}$ & 15 & 5 & 70.54 & 69.26 \\
\hline 0.5 & $\mathrm{AD}$ & 15 & 6 & 71.19 & 68.53 \\
\hline 0.5 & $\mathrm{AD}$ & 30 & 1 & 57.83 & 64.46 \\
\hline 0.5 & $\mathrm{AD}$ & 30 & 2 & 77.06 & 61.00 \\
\hline 0.5 & $\mathrm{AD}$ & 30 & 3 & 81.21 & 63.52 \\
\hline 0.5 & $\mathrm{AD}$ & 30 & 4 & 79.31 & 57.89 \\
\hline 0.5 & $\mathrm{AD}$ & 30 & 5 & 75.90 & 62.00 \\
\hline 0.5 & $\mathrm{AD}$ & 30 & 6 & 73.56 & 71.74 \\
\hline 0.5 & OD & 15 & 1 & 88.70 & 53.93 \\
\hline 0.5 & OD & 15 & 2 & 98.56 & 74.55 \\
\hline 0.5 & OD & 15 & 3 & 90.39 & 78.90 \\
\hline 0.5 & OD & 15 & 4 & 91.47 & 84.87 \\
\hline 0.5 & OD & 15 & 5 & 93.50 & 84.56 \\
\hline 0.5 & OD & 15 & 6 & 77.96 & 75.38 \\
\hline 0.5 & OD & 30 & 1 & 66.09 & 85.25 \\
\hline 0.5 & OD & 30 & 2 & 91.84 & 53.70 \\
\hline 0.5 & OD & 30 & 3 & 92.14 & 68.18 \\
\hline 0.5 & OD & 30 & 4 & 96.56 & 71.48 \\
\hline 0.5 & OD & 30 & 5 & 74.06 & 54.51 \\
\hline 0.5 & OD & 30 & 6 & 67.66 & 57.10 \\
\hline 1.0 & $\mathrm{AD}$ & 15 & 1 & 62.12 & 57.58 \\
\hline 1.0 & $\mathrm{AD}$ & 15 & 2 & 71.47 & 72.48 \\
\hline 1.0 & $\mathrm{AD}$ & 15 & 3 & 72.66 & 58.41 \\
\hline 1.0 & $\mathrm{AD}$ & 15 & 4 & 88.75 & 80.30 \\
\hline 1.0 & $\mathrm{AD}$ & 15 & 5 & 71.21 & 77.88 \\
\hline 1.0 & $\mathrm{AD}$ & 15 & 6 & 76.00 & 76.84 \\
\hline 1.0 & $\mathrm{AD}$ & 30 & 1 & 85.00 & 79.85 \\
\hline 1.0 & $\mathrm{AD}$ & 30 & 2 & 86.51 & 70.61 \\
\hline 1.0 & $\mathrm{AD}$ & 30 & 3 & 83.39 & 57.32 \\
\hline 1.0 & $\mathrm{AD}$ & 30 & 4 & 97.58 & 40.54 \\
\hline 1.0 & $\mathrm{AD}$ & 30 & 5 & 93.01 & 47.72 \\
\hline 1.0 & $\mathrm{AD}$ & 30 & 6 & 87.89 & 62.41 \\
\hline 1.0 & OD & 15 & 1 & 72.28 & 83.64 \\
\hline 1.0 & OD & 15 & 2 & 75.26 & 60.92 \\
\hline 1.0 & OD & 15 & 3 & 78.00 & 40.59 \\
\hline 1.0 & OD & 15 & 4 & 72.30 & 56.99 \\
\hline 1.0 & OD & 15 & 5 & 69.12 & 54.56 \\
\hline 1.0 & OD & 15 & 6 & 82.84 & 75.30 \\
\hline 1.0 & OD & 30 & 1 & 46.84 & 82.95 \\
\hline 1.0 & OD & 30 & 2 & 81.85 & 80.17 \\
\hline 1.0 & OD & 30 & 3 & 77.53 & 54.74 \\
\hline 1.0 & OD & 30 & 4 & 97.52 & 73.25 \\
\hline 1.0 & OD & 30 & 5 & 87.01 & 90.40 \\
\hline 1.0 & OD & 30 & 6 & 93.42 & 45.06 \\
\hline
\end{tabular}

Note: $\mathrm{I}=$ impregnated $\mathrm{NI}=$ nonimpregnated was, on average, lower than that of the nonimpregnated specimens and that the mechanical strength of the impregnated specimens, according to the estimated characteristic value, was on average higher than that of the nonimpregnated specimens under every testing condition.

It is important to examine experimental data graphically. Figure 3 presents box plots for the mean values of the impregnated and nonimpregnated specimens test according to the pressures, impregnation times and forms of drying utilized. Figure 4 is a scatter diagram of mean values versus impregnated and nonimpregnated specimens test. In Fig. 4, the square and diamond are the mean values of the average impregnated (I) and nonimpregnated (NI), respectively. Both graphs indicate that compression strength of impregnated wood specimens is greater than that of nonimpregnated. Another way of testing the equality of several means is the

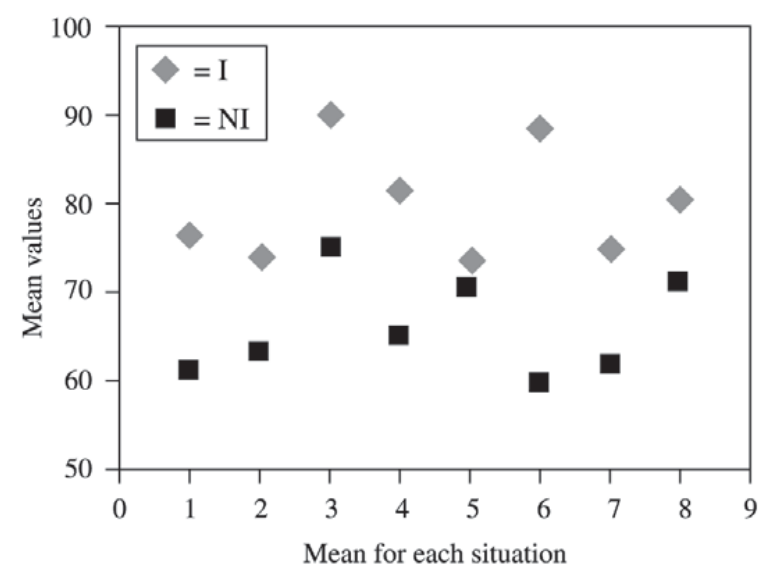

Figure 3. Scatter diagram for the mean values versus mean for each situation.

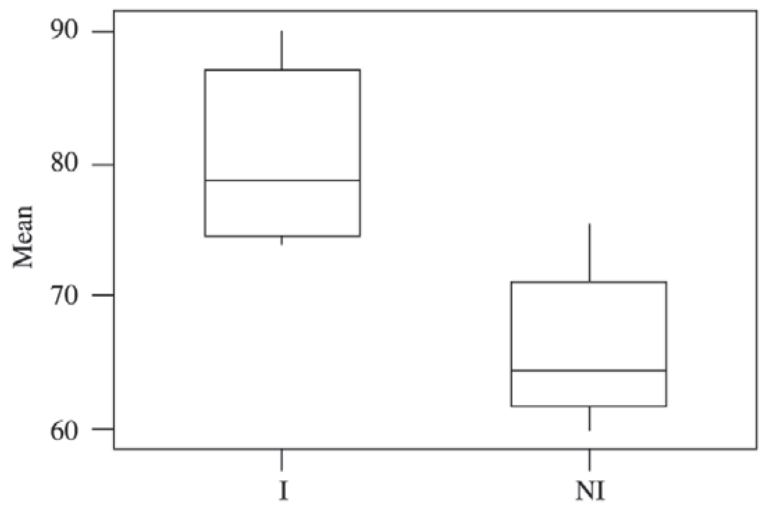

Figure 4. Box plots of mean values of the impregnated and nonimpregnated specimens test. 
Table 2. Values of the impregnated and nonimpregnated Eucalyptus grandis.

\begin{tabular}{ccccccccccc}
\hline Time & Drying & Pressure & \multicolumn{2}{c}{$\bar{x}$} & \multicolumn{2}{c}{$s$} & \multicolumn{2}{c}{ CV } & ECV \\
\hline & & & I & NI & I & NI & I & NI & I & NI \\
15 & AD & 0.5 & 76.56 & 61.23 & 8.07 & 11.21 & 10.54 & 18.30 & 63.33 & 42.85 \\
30 & AD & 0.5 & 74.15 & 63.44 & 8.42 & 4.66 & 11.36 & 7.35 & 60.33 & 55.78 \\
15 & OD & 0.5 & 90.10 & 75.36 & 6.85 & 11.38 & 7.60 & 15.10 & 78.86 & 56.70 \\
30 & OD & 0.5 & 81.39 & 65.04 & 13.65 & 12.35 & 16.77 & 18.99 & 59.00 & 44.79 \\
15 & AD & 1.0 & 73.70 & 70.58 & 8.70 & 10.08 & 11.80 & 14.27 & 59.44 & 54.06 \\
30 & AD & 1.0 & 88.90 & 59.74 & 5.38 & 14.48 & 6.05 & 24.24 & 80.08 & 35.99 \\
15 & OD & 1.0 & 74.97 & 62.00 & 4.89 & 15.40 & 6.53 & 24.83 & 66.94 & 36.75 \\
30 & OD & 1.0 & 80.70 & 71.10 & 18.12 & 17.58 & 22.46 & 24.73 & 50.97 & 42.26 \\
\hline
\end{tabular}

Note: $\mathrm{I}=$ impregnated $\mathrm{NI}=$ nonimpregnated

Table 3. Analysis of variance for the data of Table 2 .

\begin{tabular}{cccccc}
\hline $\begin{array}{c}\text { Source } \\
\text { of variation }\end{array}$ & SS & DF & MS & $\mathrm{F}_{\text {cal }}$ & $\mathrm{p}$ \\
\hline $\begin{array}{c}\text { Between } \\
\text { treatments }\end{array}$ & 783.7 & 1 & 783.7 & 21.32 & 0.000 \\
$\begin{array}{c}\text { Within treatments } \\
\text { (Residues) }\end{array}$ & 514.6 & 14 & 36.8 & & \\
$\quad$ Total & 1298.3 & 15 & & & \\
\hline
\end{tabular}

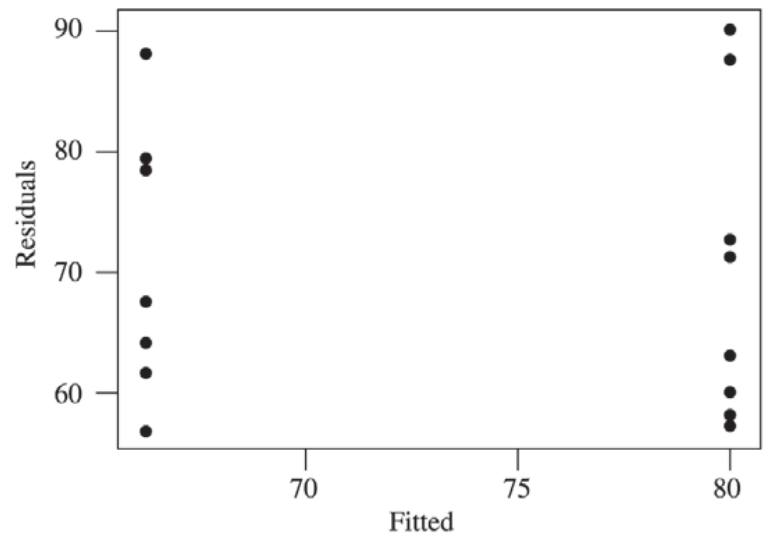

Figure 5. Residues versus estimated values.

analysis of variance.

An analysis of variance was made to verify whether the mean difference between the impregnated and nonimpregnated specimens was statistically significant, after checking the basic assumptions for a variance analysis ${ }^{6}$. The graph in Fig. 5 is based on this verification and shows the residues versus the estimated values, indicating that the variance is constant and that the suppositions of normality were also met.
The analysis of variance can therefore be used to make inferences about the data, as shown in Table 3.

Hence, with the data of Table 3 , it was confirmed that the averages of the two treatments were not the same, allowing us to consider the following hypothesis test, from the standpoint of treatment effects:

$$
\left\{\begin{array}{l}
H_{0}: \tau_{1}=\tau_{2}=\cdots=\tau_{k}=0 \\
H_{1}: \tau_{t} \neq 0, \quad \text { for at least one } i
\end{array}\right.
$$

Thus, for one level of significance, $\alpha=0.05$. The hypothesis must be rejected if $F_{c a l}>F_{t a b}, F_{c a l}$, i.e., the region of rejection is $R: F_{c a l}>F_{0.05 ;(k-1) ;(n-k)}$. Therefore, from Table F with $(2-1)=1$ degrees of freedom and $(16-2)=14$ degrees of freedom, one has $F_{0.05 ;(1 ; 14)}=4.60$, i.e., the region of rejection is $R: F_{\text {cal }}>4.60$.

From the data observed, the statistics of the test, aimed at rejecting or accepting the null hypothesis of the treatments, is given by the ratio $F_{c a l}$, i.e.:

$$
F_{\text {cal }}=\frac{783.7}{36.8}=21.32
$$

Statistical decision: Since $F_{\text {cal }}=21.32>4.6$ reject $H_{0}$ at significant level of $\alpha=0.05$.

According to the data, at a level of significance of $\alpha=0.05$, one can conclude that the two types of treatment lead to dissimilar means values of compressive strength.

Note that the same conclusions are reached for these treatments when one considers the $\mathrm{p}$ value of Table 3 and a level of $\alpha=0.05$, i.e., $H_{0}$ is rejected. In this case, the $\mathrm{p}$ value of treatments is 0.000 , keeping in mind that $H_{0}$ is rejected if the $\mathrm{p}$ value of the test is lower than a level a $(0.01<\alpha<0.05)$.

Note, also, that the mean of the impregnated test specimens is 80.06 while that of the nonimpregnated ones is 66.06. Therefore, this difference is statistically significant. In other words, the compressive strength of the impregnated specimens is greater than that of the nonimpregnated ones. 
It is worth noting that, in this case, no alternative test is necessary since only two types of treatment were performed (with and without impregnation).

\section{Conclusions}

The results of these tests demonstrated that the compressive strength of impregnated wood specimens is greater than that of nonimpregnated ones, indicating that monocomponent polyurethane resin can be considered suitable for impregnating wood, since it increases the compressive strength of Eucalyptus grandis. It should be noted that the highest average strength (90.10) for a pressure of $0.5 \mathrm{MPa}$ was obtained with a $15 \mathrm{~min}$ impregnation time and oven drying. On the other hand, for a pressure of $1 \mathrm{MPa}$, the best average compressive strength (88.90) was obtained with 30 min of impregnation and drying in air.

\section{References}

1. Dinwoodie, M.J. Wood: Nature's Cellular, Polymeric Fibre-Composite the Institute of Metals. Londres, Inglaterra, 1989.
2. Gomes, O.F. Estudo das ligações cavilhadas com resinas estirênas empregadas em estruturas de madeiras. Tese de Doutorado - EESC, 1996.

3. Hartshon, S.R. Structural Adhesives Chemistry and technology Plenum. Press New York, 1986.

4. Martínez, M.E. Desenvolvimento de um Modelo Estatístico para Aplicação no Estudo de Fadiga em Emendas Dentadas de Madeira. Tese (Doutorado) Escola de Engenharia de São Carlos/Instituto de Física de São Carlos/Instituto de Química de São Carlos da Universidade de São Paulo. São Carlos, SP, 2001.

5. Miles, D.C.; Briston, J.H. Polymer Technology. Chemical Publishing, New York, p.195, 1979.

6. Montgomery, J.S. Diseño y Análisis de Experimentos. Editora Panamericana S.A. México, 1991.

7. Myers, R.H.; Montgomery, D.C. Response Surface Methodology: Process and Product Optimization Using Designed Experiments. John Wiley \& Sons, Inc., New York, 1995.

8. NBR - 7190/97 - (Projeto de Estruturas de Madeira), Rio de Janeiro, ABNT, 1997.

9. Tsoumis, G.I. (1991). Science And Technology of Wood. Van Nostrand Reinhold. 
